\title{
Analisis Peran Stakeholders dalam Pengembangan Pariwisata Siosar
}

\section{Analysis Of The Role of Stakeholders in Siosar Tourism Development}

\author{
Grace Ginting, Kismartini, Tri Yuniningsih \& Teuku Afrizal*
}

\author{
Program Studi Magister Administrasi Publik, Fakultas Ilmu Sosial dan Ilmu Politik, \\ Universitas Diponegoro, Indonesia
}

Diterima: 15 Mei 2021; Direview: 15 Mei 2021; Disetujui: 29 November 2021

\begin{abstract}
Abstrak
Siosar merupakan salah satu kawasan wisata yang berada di Kabupaten Karo, Sumatera Utara. Pengembangan pariwisata kawasan wisata Siosar melibatkan peran-peran stakeholder yaitu pemerintah, swasta dan masyarakat. Peran stakeholder diperlukan untuk melakukan pengembangan termasuk pengembangan pariwisata agar dapat dilakukan secara optimal. Stakeholder adalah individu ataupun kelompok yang terlibat dalam pengembangan pariwisata. Tujuan penelitian ini adalah menganalisis peran-peran dari stakeholder dalam mengembangkan kawasan wisata Siosar. Metode penelitian yang digunakan yaitu studi literature review. Hasil penelitian menunjukkan bahwa peran stakeholder dalam pengembangan kawasan wisata Siosar belum signifikan. Siosar merupakan kawasan wisata yang memiliki potensi alam, agrowisata, dan lainnya yang harus dikembangkan dengan baik. Masing-masing stakeholder menjalankan perannya, namun belum memberikan hasil yang optimal, masih adanya ketimpangan peran dan kendala yang dihadapi menunjukkan bahwa stakeholder belum sepenuhnya menjalankan perannya, baik peran pemerintah, swasta hingga masyarakat. Belum optimalnya peran stakeholder tersebut dikarenakan belum adanya kerjasama dan komunikasi yang terjalin dengan baik. Pemerintah daerah sudah seharusnya menggandeng pihak swasta dan masyarakat untuk berupaya dalam pengembangan pariwisata, sehingga pengembangan pariwisata kawasan wisata Siosar dapat lebih optimal dan signifikan.
\end{abstract}

Kata Kunci: Stakeholder; Pengembangan Pariwisata; Siosar

\begin{abstract}
Siosar is one of the tourist areas located in Karo Regency, North Sumatra. The tourism development of Siosar tourism area involves the roles of stakeholders, namely government, private sector and community. The role of stakeholders is needed to carry out development including tourism development so that it can be carried out optimally. Stakeholders are individuals or groups involved in tourism development. The purpose of this research is to analyze the roles of stakeholders in developing the tourism area of Siosar. The research method used is a literature review study. The results showed that the role of stakeholders in the development of the Siosar tourism area was not significant. Siosar is a tourist area that has natural potential, agro-tourism, and others that must be developed properly. Each stakeholder plays its role, but has not given optimal results, there are still imbalances in roles and the obstacles faced indicate that stakeholders have not fully played their roles, both the roles of the government, the private sector and the community. The role of stakeholders is not yet optimal because there is no cooperation and communication that is well established. The local government should have collaborated with the private sector and the community to make efforts in developing tourism, so that tourism development in the Siosar tourism area can be more optimal and significant.
\end{abstract}

Key Words: Stakeholder; Tourism Development; Siosar

How to Cite: Ginting, G. Kismartini, Yuniningsih, T. \& Afrizal, T. (2022). Analisis Peran Stakeholders dalam Pengembangan Pariwisata Siosar. PERSPEKTIF, 11 (1): 8-15

\begin{tabular}{lr}
\hline *Corresponding author: & ISSN 2085-0328 (Print) \\
E-mail: grace@gmail.com & ISSN 2541-5913 (online)
\end{tabular}




\section{PENDAHULUAN}

Pariwisata merupakan sektor industri yang memiliki peluang dan pengaruh dalam mendukung perekonomian Indonesia. Terlihat dari minat wisatawan mancanegara yang masih banyak datang ke Indonesia. Indonesia sebagai salah satu negara yang memiliki banyak kekayaan alam menjadikan daya tarik tersendiri bagi wisatawan sehingga minat untuk berkunjung tinggi. Dalam Bramana mengatakan, Indonesia setidaknya memiliki 11 provinsi yang banyak dikunjungi oleh wisatawan mancanegara, yaitu Bali, DKI Jakarta, Daerah Istimewa Yogyakarta, Jawa Timur, Jawa barat, Banten, Lampung, Sulawesi Selatan, Sumatera Selatan, Sumatera Barat dan Sumatera Utara (BPS, 2015)

Sumatera Utara merupakan salah satu provinsi di Indonesia yang memiliki keanekaragaman daya tarik pariwisata. Tidak hanya memiliki daya tarik wisata alam serta buatan, tetapi juga wisata peninggalan sejarah dan adat budayanya. Salah satunya yaitu Desa Siosar yang terletak di Kabupaten Karo. Siosar menjadi salah satu daerah tujuan wisata yang masih menarik minat wisawatan baik dari lokal, domestik hingga mancanegara. Selain karena pemandangan alam dan udaranya yang sejuk, Siosar juga memiliki sejarah yang unik, sehingga semakin menarik wisatawan (Sinuhaji dkk, 2019).

Siosar adalah desa baru yang lahir tepat setelah meletusnya Gunung Sinabung beberapa tahun lalu. Desa ini diperuntukkan bagi masyarakat korban erupsi Sinabung yang desanya tidak dapat ditempati lagi. Siosar merupakan kawasan perbukitan yang memiliki potensi sebagai kawasan wisata. Beberapa puncak gunung yang memiliki pemandangan indah dapat dinikmati di kawasan ini. Melalui adanya pengembangan pariwisata di wilayah Siosar, pemerintah mengharapkan masyarakat yang tinggal di wilayah Siosar mampu memanfaatkan peluang positif.

Potensi-potensi wisata yang ada di Siosar ini sungguh sangat disayangkan apabila tidak dikembangkan dengan baik. Potensi wisata ini dapat dikatakan menjanjikan untuk meningkatkan pendapatan masyarakat setempat. Memiliki udara yang sejuk, berada di atas $2000 \mathrm{~m}$ diatas laut dan pemandangan alam yang indah, Siosar menjadi destinasi wisata yang ramai dikunjungi oleh wisatawan. Melihat potensi yang dimiliki oleh Siosar ini, maka sudah seharusnya pemerintah melakukan upaya guna pengembangan sektor pariwisata (Fahrizal dkk, 2020).

Tabel 1: Jumlah Kunjungan Wisatawan Kabupaten Karo

\begin{tabular}{ll}
\hline TAHUN & Jumlah Kunjungan \\
\hline 2016 & $26,61 \%$ \\
\hline 2017 & $26,02 \%$ \\
\hline 2018 & $27,41 \%$ \\
\hline 2019 & $32,27 \%$ \\
\hline 2020 & $19,36 \%$ \\
\hline
\end{tabular}

Sumber: BPS 2021

Berdasarkan data kunjungan wisatawan yang berkunjung ke Tanah Karo menunjukkan bahwa setiap tahunnya, Tanah Karo masih menjadi pilihan bagi wisatawan. Namun, di tahun 2020 kunjungan wisatawan ini mengalami penurunan yang signifikan dikarenakan adanya pandemic Covid-19. Jumlah wisatawan yang menurun hingga mencapai $13 \%$ ini yang perlu dicari solusi dan jalan keluarnya. Maka untuk semakin meningkatkan kunjungan wisawatan tentu dibutuhkan adanya kerja sama yang baik dengan seluruh pihak guna pengembangan pariwisata Siosar (Simamora dkk, 2016).

Pengembangan sektor pariwisata merupakan salah satu cara yang dapat meningkatkan pendapatan suatu daerah. Pengembangan pariwisata dilakukan agar sektor wisata dapat meningkatkan kualitasnya sehingga semakin dikenal dan diakui. Berkembangnya pariwisata di suatu daerah akan mendatangkan banyak manfaat bagi masyarakat, baik secara ekonomis, sosial dan budaya. Pariwisata memiliki peran serta dalam pengembangan ekonomi lokal bagi masyarakat, terciptanya padat karya yang dapat menciptakan pendapatan bagi penduduk (Suharyanto, et al., 2020; Lubis, et al., 2020; Suharyanto, et al., 2019). 
Pemerintah tidak dapat bergerak sendiri dalam mengelola objek wisata. Masyarakat harus aktif dan berkontribusi untuk membantu pemerintah dalam mengelola dan mengembangkan daerah wisata. Pengembangan wisata harus dilakukan dengan optimal, melihat banyaknya sumber daya alam yang berpotensi menjadi daerah wisata. Keuntungan dari pengembangan daerah wisata yang tepat akan meningkatkan devisa yang masuk dan juga memajukan daerah tersebut. Pengembangan wisata di suatu daerah tentu membutuhkan peranan dan kontribusi dari stakeholders terkait.

Stakeholder memiliki peranan penting dalam suatu pengembangan suatu objek wisata. Stakeholder merupakan suatu individu ataupun kelompok ataupun organisasi yang memiliki kepentingan, keterlibatan dan pengaruh oleh kegiatan ataupun program pembangunan (Hetifah dalam Reski, 2016). Dalam setiap kegiatan pembangunan, para stakeholder memiliki sumber daya dan kepentingan masing-masing yang harus terwakili dalam proses pengambilan keputusan, sehingga pengembangan pariwisata suatu daerah dapat terealisasi dengan optimal.

Adapun Rahmi (dalam Alamsyah 2016) mengatakan dalam suatu pengembangan pariwisata ada tiga stakeholder yang sangat berperan penting, yaitu pemerintah, swasta, dan masyarakat. Stakeholders memiliki peranan penting dalam pengembangan pariwisata, tanpa adanya peran dari stakeholders setempat, pengembangan pariwisata di daerah tidak dapat berjalan dengan maksimal. "Keterlibatan peran stakeholders menghasilkan perencanaan strategi pariwisata yang diterima dengan baik, menghindari konflik yang timbul selama implementasi kebijakan dan menyatukan mereka yang secara langsung dan tidak langsung terlibat dalam pariwisata" (Wanner, 2019).

Dalam pengembangannya kawasan wisata di Siosar sudah terkelola dengan baik, namun pelaksanaannya masih belum maksimal. Hal ini terlihat dari peran-peran pemerintah daerah belum terlihat secara sepenuhnya dalam mendukung pengembangan pariwisata Siosar, seperti ketersediannya fasilitas, sarana dan prasarana yang belum sesuai. Akses perjalanan yang sulit dan jauh, jalan yang kecil dan sempit serta mengalami kerusakan di beberapa titik, masih adanya kemacatan, lokasi parkir yang sulit, banyaknya sampah, dan toilet yang tidak bersih.. Masih adanya sampah yang berserakan di beberapa tempat wisata, fasilitas-fasilitas umum yang tidak terawat.

Fokus dalam penelitian ini adalah untuk menganalisis peran-peran stakeholder dalam mengembangkan pariwisata di kawasan Siosar. Pengembangan kawasan wisata Siosar menjadi penting dan membutuhkan peran stakeholder terkait dikarenakan Siosar kawasan wisata yang baru dan sangat perlu untuk dikembangkan dengan potensi yang cukup besar, namun pengelolaan yang belum maksimal masih menjadi kendala. Maka, perlu suatu solusi agar peran para stakeholder dapat berjalan dengan baik dan maksimal dan memberikan dampak yang besar pula pada pengembangan wisata Siosar. Oleh karena itu, peran-peran stakeholder penting untuk dapat ditinjau kembali.

\section{METODE PENELITIAN}

Penulisan dalam penelitian ini menggunakan pendekatan kualitatif dengan metode penelitian studi tinjauan pustaka (literature view) dari berbagai sumber yang terkait dengan peran stakeholder, pengembangan pariwisata, seperti penelitian sebelumnya dan disusun dari beberapa pencarian yang didapatkan. Tinjauan literature dilakukan dari berbagai sudut pandang yang dapat dilihat kebenarannya. Sumber data diperoleh dari data sekunder. Data sekunder dikumpulkan melalui telaah dan eksplorasi jurnal, buku, dan dokumen yang relevan dengan peran stakeholder dalam pengembangan pariwisata Siosar. Pengumpulan data dilakukan dengan menggunakan Observasi, yaitu pengumpulan data melalui pengamatan langsung yang mengamati kondisi objek wisata dan mengamati peran serta pemerintah, swasta, dan masyarakat dalam mengembangkan wisata.

\section{HASIL DAN PEMBAHASAN \\ Pengembangan Pariwisata di Siosar}

Desa Siosar merupakan salah satu desa yang memiliki banyak pesona wisata. Berada di daratan tinggi, 1750 meter diatas laut di Kecamatan Merek, Kabupaten Karo, Sumatera Utara, Siosar menjadi satu dari banyaknya tempat wisata yang layak untuk dikunjungi wisatawan. 
Memiliki pesona wisata alam yang indah, pilihan objek wisata yang banyak, udara yang segar dan sejuk, Siosar masih menjadi pilihan untuk dikunjungi.

Berawal dari hutan lindung yang luas, Siosar berubah menjadi kawasan relokasi bagi pengungsi Gunung Sinabung, kemudian Siosar disulap menjadi satu destinasi wisata yang menarik. Siosar sendiri memiliki perkembangan yang pesat dalam mengembangkan pariwisatanya. Tidak hanya memiliki objek wisata alam, Siosar juga menawarkan wisata agrowisata dan wisata kuliner yang patut untuk dicoba.

Dalam 3 tahun terakhir ini, Siosar semakin mengembangkan kawasan wisata di daerahnya. Pelaku wisata semakin banyak untuk membuka tempat-tempat wisata. Beberapa objek wisata yang ada di Siosar, yaitu:

Tabel 2: Daftar Objek Wisata Siosar

\begin{tabular}{ll}
\hline Tempat Wisata & Jenis Wisata \\
\hline Kebun Madu Efi Siosar & Agrowisata \\
\hline Puncak 2ooo Siosar & Wisata Alam \\
\hline Relokasi Huntap Siosar & Wisata Alam \\
\hline Taman Bunga Sapo Juma & Agrowisata \\
\hline Emisura Taman Wisata Puncak Siosar & Agrowisata \\
\hline Zia Coffee & Wisata Kuliner \\
\hline \multicolumn{2}{c}{ Sumber : Google } \\
\end{tabular}

Banyaknya tempat-tempat wisata yang ada menunjukkan bahwa, kawasan wisata Siosar ini menunjukkan perkembangan yang signifikan. Pengembangan kawasan wisata Siosar semakin giat dilakukan untuk semakin menarik minat wisatawan yang berkunjung. Hal ini terlihat dari semakin meningkatnya kunjungan wisatawan ke Kabupaten Karo, yang meningkat setiap tahunnya dari tahun 2016 hingga tahun 2020, setidaknya meningkat sebesar 6\% hingga mencapai di angka $32,27 \%$.

\section{Peran Stakeholder dalam Pengembangan Pariwisata Siosar}

Pertama adalah Pemerintah. Dalam upaya pengembangan pariwisata Siosar tentu harus ada keterlibatan dan adanya campur tangan dari stakeholder. Pemerintah daerah yang dimaksudkan salah satunya yaitu Dinas Pariwisata dan Kebudayaan Kabupaten Karo. Dinas Pariwisata dan Kebudayaan Kabupaten Karo memiliki 4 peranan penting dalam upaya pengembangan pariwisata, yaitu sebagai wirausaha, stimulator, koordinator dan fasilitator.

Sebagai Wirausaha. Peran pemerintah sebagai wirausaha belum terlaksana dengan baik. Terlihat dari beberapa keluhan masyarakat dan pelaku wisata yang masih belum merasakan peran dari pemerintah setempat. Pelaku wisata contohnya seperti di salah satu tempat wisata, merasa pemerintah belum mampu memanfaatkan wirausaha bagi mereka pelaku wisata yang berjualan disekitar objek wisata. Pemerintah juga belum memanfaatkan BUMDes Siosar dalam proses pengembangan wisata, sedangkan BUMDes dinilai sangat bermanfaat.

Sebagai Stimulator. Selanjutnya yaitu, peran sebagai stimulator. Peran sebagai stimulator juga belum dapat dirasakan secara maksimal oleh masyarakat, khususnya bagi pelaku wisata. Mereka masih merasa pemerintah belum melakukan tindakan-tindakan khusus dan membantu di dalam menyediakan fasilitas-fasilitas promosi untuk mendukung pembangunan pariwisata Siosar dan belum merasakan dampak nyata akan peran pemerintah..

Sebagai Koordinator. Dalam mengkoordinasi, Dinas Pariwisata dan Kebudayaan Kabupaten Karo menetapkan kebijakan-kebijakan mengenai daerah wisata, tetapi yang terjadi di lapangan pemerintah hanya menetapkan saja kebijakan-kebijakan tersebut secara lisan. Pemerintah hampir tidak pernah melibatkan masyarakat maupun pelaku wisata yang ada, sehingga masyarakat maupun pelaku wisata tidak dapat memahami kebijakan-kebijakan yang ditetapkan dan akhirnya menimbulkan miss communication.

Sebagai Fasilitator. Terakhir, peran pemerintah sebagai fasilitator yaitu menyediakan fasilitas sarana dan prasarana di daerah wisata guna mendukung pengembangan pariwisata Siosar, seperti toilet umum yang bersih, tong sampah, tempat duduk dan layanan publik lainnya belum terlihat. Namun, yang terlihat di lapangan justru masyarakat sendiri atau pelaku wisata 
yang lebih banyak menyediakan fasilitas untuk pengunjung sehingga mengurangi peran pemerintah sebagai fasilitator. Bahkan, tidak jarang barang-barang atau layanan publik ini lebih banyak diberikan oleh pihak luar seperti universitas-universitas yang melakukan penelitian ataupun pengabdian.

Melalui Pemerintahan Kabupaten Karo, mereka memberikan fasilitas moda transportasi seperti bus yang berguna digunakan untuk wisatawan atau masyarakat setempat yang ingin bepergian dari Kabanjahe menuju Siosar dan sebaliknya Siosar menuju Kabanjahe. Tetapi, bus ini masih berjumlah sangat sedikit sehingga apabila ingin menggunakan bus ini wisatawan maupun masyarakat harus menunggu lama.

Selain itu, beberapa objek wisata yang ada di Siosar masih banyak dipegang oleh pihak swasta ataupun pelaku swasta. Hal ini menunjukkan bahwa peran pemerintah belum maksimal turut andil dalam pengembangan pariwisata Siosar. Dinas Pariwisata dan Kebudayaan harusnya menciptakan hubungan kerjasama serta koordinasi antara stakeholder pariwisata agar mempermudah kinerja pemerintah daerah dalam upaya pengembangan kawasan objek wisata baik swasta maupun masyarakat.

Kedua adalah Swasta. Kemajuan suatu industri pariwisata tentu tidak lepas dari peran swasta sebagai lembaga pengelola. Swasta sebagai pemilik modal yang kuat, cepat dan tanggap dalam mengikuti perkembangan trend serta pengelola bisnis memiliki peranan dalam menyediakan sarana dan prasarana sebagai penunjang bagi pariwisata. Pariwisata membutuhkan banyak sarana pendukung seperti, akomodasi, informasi, travel agent, transportasi, restoran dan lain-lain, sehingga dapat menarik wisatawan dan memberikan kepuasan kepada wisatawan (Yoeti, 1996). Sektor swasta bersifat lebih unggul dalam mengikuti perkembangan jaman, memiliki keunggulan modal, serta lebih fleksibel dalam melakukan kegiatan bisnis. Dilibatkannya pihak swasta, memunculkan harapan swasta mampu menciptakan inovasi dan terobosan yang unik dan menarik bagi pariwisata, serta membantu pemerintah membuka lapangan kerja yang berguna untuk mengurangi angka pengangguran.

Swasta memiliki kapabilitas yang memberikan dampak besar bagi. Dalam Cahyo, Lickorish dkk (1994) mengatakan bahwa "sektor swasta memiliki lima peran utama dalam pengembangan sebuah destinasi wisata. Ke lima peran tersebut adalah sektor swasta sebagai agen pembangunan dan penyediaan sarana akomodasi, penyedia toko perbelanjaan, penyedia sarana hiburan, pendukung sarana transportasi, dan yang terakhir berperan sebagai pendukung pengembangan atraksi wisata"

Peran swasta dalam menyediakan akomodasi seperti transportasi dan penginapan belum terlaksana secara optimal. Hal ini dikarenakan kawasan wisata Siosar masih destinasi wisata yang baru, sehingga tidak memiliki akomodasi terlalu banyak tetapi hanya beberapa saja. Salah satunya penginapan bergaya nuansa klasik yang belakangan ini memiliki daya tarik yang tinggi bagi pengunjung, yaitu villa dengan desain klasik ala Eropa. Tidak hanya berada satu titik, penginapan atau villa yang dibangun dengan desain klasik ala Eropa ini mulai banyak dibangun oleh pelakupelaku wisata di Siosar. Ada yang menamakan dengan "Villa Siosar Puncak 2000", dan lainnya. Selain daripada villa di Siosar ini, belum ada penginapan lain yang tersedia disana seperti hotel di daerah Siosar. Apabila wisatawan ingin menginap dihotel, wisatawan harus kembali turun menuju Kabanjahe dan Berastagi yang lebih banyak menyediakan penginapan.

Sama halnya dengan moda transportasi, sejauh ini peran swasta dalam menyediakan sarana transportasi belum terpenuhi. Hal ini terlihat dari belum adanya akses menuju Siosar dengan transportasi umum yang di fasilitasi oleh pihak swasta. Maka, lebih banyak para wisatawan yang berkunjung menggunakan kendaraan pribadi, seperti mobil dan motor pribadi atau menyewa bus apabila dengan rombongan keluarga. Padahal apabila penyediaan moda transportasi ini disediakan oleh pihak swasta tentu akan memberikan keuntungan kepada moda transportasi serta wisatawan karena akan merasa lebih mudah dalam mengakses perjalanan menuju Siosar.

Swasta sebagai penyedia akomodasi, transportasi serta fasilitas wisata lainnya, harus melakukan perbaikan dan pembaharuan untuk bisa memberikan rasa aman dan nyaman serta kepuasan bagi wisatawan. Pihak swasta juga tidak berperan sebagai investor saja dalam pembangunan sarana dan prasaran, tetapi juga dapat bekerja sama guna mengelola dan mengatasi berbagai kekurangan yang ada dalam pariwisata. Cahyo mengatakan sektor swasta memiliki 
peranan penting dalam mendukung kegiatan perekonomian di daerah wisata yang dikembangkan. Kekuatan dari masing-masing sektor akan membantu dalam mengatasi kelemahan dari sektor lain, dan begitu sebaliknya bagi pemerintah maupun swasta, sehingga tujuan yang ingin dicapai dalam pembangunan pariwisata dapat berjalan maksimal.

Ketiga adalah Masyarakat. Masyarakat juga memiliki peranan dalam mengelola objek wisata, begitu juga dengan masyarakat sekitar Siosar ini. Pengelolaan objek-objek wisata bisa dilakukan dengan menjadi pelaku-pelaku usaha dengan membuka usaha disekitar kawasan Siosar, seperti menyediakan penginapan, warung makan atau restoran. Masyarakat juga dapat berperan dengan memberikan kontribusi dalam pengembangan pariwisata, seperti memberikan idemasukan, tenaga, kekayaan, keterampilan dan sosial.

Masyarakat dituntut untuk dapat berperan aktif dalam pengelolaan objek wisata. Mereka dapat memanfaatkannya dengan baik sebagai kesempatan bekerja dan usaha jasa wisata. Selain itu, masyarakat juga berperan untuk dapat menjaga dan merawat lingkungan alam, dan tidak melakukan tindakan yang dapat merusak lingkungan alam. Namun, masyarakat diajak untuk semakin menambahkan keindahan alam, seperti menanam bunga yang akan semakin memperindah wisata.

Selain itu, masyarakat juga bisa berperan dengan membuka usaha pendukung kegiatan pariwisata. Beberapa masyarakat yang memiliki keterampilan, mereka bisa membuka usahausaha seperti warung kopi kekiniaan/coffee shop. Di Puncak Siosar, ada warung yang menjual makanan dan minuman seperti teh manis, indomie dan makanan ringan. Mereka menyediakan meja dan tempat duduk yang langsung berhadapan dengan pemandangan alam. Walaupun warungnya terlihat kecil, wisatawan yang ingin duduk santai sambil menikmati angin pun tertarik ingin mencoba. Ada juga salah satu masyarakat yang membuka coffee shop yang dinamakan "Mejuah-Mejuah Coffee", dengan desain bangunan yang unik dan memiliki alat live music, coffee shop ini mampu menarik wisatawan yang ingin berkunjung sambil mendengarkan musik. Usahausaha yang dilakukan salah satu masyarakat ini sudah menunjukkan bahwa masyarakat mampu berperan dalam pengembangan wisata di Siosar.

Peran masyarakat juga belum sepenuhnya terjalankan karena adanya keterbatasan kemampuan masyarakat dalam pengembangan kreatifitas karena adannya keterbatasan modal, sehingga dalam membuat kreatifitas masyarakat membutuhkan modal serta adanya sosialisasi daerah potensi wisata sebagai langkah meningkatkan kesejahteraan masyarakat sekitar.

Dalam menjalankan perannya, masyarakat setempat di Siosar nampaknya masih belum memberikan kontribusi yang penuh. Masyarakat yang mengelola tempat wisata nyatanya masih kurang dalam merawat kebersihan dari objek wisata yang ada. Mereka terkesan memberikan pelayanan hanya untuk mendapatkan pendapatan saja. Melalui masyarakat diharapkan adanya pengembangan kawasan wisata yang signifikan. Masyarakat juga belum sepenuhnya dilibatkan dalam proses pengambilan kebijakan dalam upaya pengembangan kawasan wisata Siosar, sehingga masyarakat menganggap aspirasi mereka kurang diperhatikan oleh pemerintah setempat.

\section{SIMPULAN}

Hasil penelitian di atas menunjukkan bahwa, Siosar mempunyai potensi wisata yang besar untuk dikembangkan. Memiliki banyak objek wisata yang berpotensi, sudah seharusnya stakeholder melakukan berbagai upaya dalam pengembangan kawasan wisata di Siosar. Berdasarkan hasil penelitian, diperoleh kesimpulan bahwa dalam menjalankan perannya, stakeholder terkait belum melakukan perannya secara optimal. Masih ditemukannya ketidaksesuaian yang terjadi di lapangan dengan yang seharusnya, baik dari Pemerintah, swasta dan masyarakat. Dinas Pariwisata dan Kebudayaan terlihat belum memiliki andil besar, pihak swasta juga belum menyediakan fasilitas seperti yang diharapkan, dan masyarakat yang belum di dilibatkan dalam proses pengembangan kawasan wisata di Siosar. Pemerintah Daerah Kabupaten Karo melalui Dinas Pariwisata dan Kebudayaan setempat, sudah seharusnya melakukan perencanaan yang optimal dalam upaya pengembangan objek-objek wisata di Siosar. Dinas Pariwisata dan Kebudayaan sebagai stakeholder yang memiliki hak dan wewenang dalam menciptakan kebijakan, seharusnya mengambil langkah tepat dalam pengembangan kawasan 
wisata Siosar. Selain itu juga dapat menggandeng dan mengajak pihak swasta agar dapat bekerja sama dalam pengembangan pariwisata di Tanah Karo, khususnya Siosar sebagai destinasi wisata yang masih baru dan fresh. Serta lebih mengandalkan dan memanfaatkan masyarakat setempat guna mendukung dan memfasilitasi keberhasilan pengembangan kawasan wisata Siosar. Peranperan stakeholder ini yang kemudian harus dikaji ulang, agar pengembangan kawasan wisata Siosar dapat berjalan dengan optimal dan maksimal, sehingga Siosar semakin berkembang semakin dikenal, dan semakin ramai dikunjungi.

\section{DAFTAR PUSTAKA}

Amalyah, R. Hamid, D \& Hakim, L. (2016). Peran Stakeholder Pariwisata Dalam Pengembangan Pulau Samalona Sebagai Destinasi Wisata Bahari. Jurnal Administrasi Bisnis. 37 (1)

Badan Pusat Statistik Provinsi Sumatera Utara, website: https://sumut.bps.go.id/indicator/ 16/89/1/tingkat-penghunian-kamar-hotel-dan-akomodasi-lainnya-menurut-kabupaten-kota.html , diakses pada tanggal 16 April 2021)

Bibin, M. Vitner \& Imran. (2018). Analysis of Stakeholder in The Development of Lambobo Beach Sustainable Town in Palopo City. Jurnal Masyarakat, Kebudayaan dan Politik. 31 (1): 62-71.

Cahyana, S \& Nugroho S. (2019). Analisis Peran Stakeholder Desa Wisata Carangsari, Kecamatan Petang, Kabupaten Badung. Jurnal Destinasi Pariwisata. 7(2)

Cahyo, E \& Nuryanti W. (2018). Peran Sektor Pemerintah Dan Swasta Dalam Perkembangan Destinasi Wisata Di Kabupaten Pulau Morotai. Gadjah Mada Journal of Tourism Studies. 1(2)

Destiana, R. Kismartini \& Yuniningsih, T . (2020). Analisis Peran Stakeholders Dalam Pengembangan Destinasi Pariwisata Halal Di Pulau Penyengat Provinsi Kepulauan Riau. Jurnal Ilmu Administrasi Negara. 8(2)

Fahrizal, M.Y, Hendra, Y. \& Hidayat, T.W. (2020). Opini Publik Tentang Destinasi Pariwisata Danau Toba Sebagai Global Geopark Kaldera UNESCO Melalui Website Kompas.Com. Ilmu Pemerintahan, Administrasi Publik, Ilmu Komunikasi (JIPIKOM), 2(1) 2020: 19-24,

Ginting, R. F \& Fewidarto, P.D. (2018). Model Pengembangan Desa Wisata di Kabupaten Karo Provinsi Sumatera Utara. Skripsi. Institut Pertanian Bogor.

Ginting, R.P \& Suryawan, I.B . (2017). Strategi Pengembangan Daya Tarik Wisata Bukit Gundaling Di Kabupaten Karo. Jurnal Destinasi Pariwisata. 5(1)

Google, Objek-Objek Wisata di Siosar, website: https://www.google.com/search?q=objekobjek+wisata + di + siosar\&oq=objek-

objek+wisata+di+siosar\&aqs=chrome.0.69i59j69i57j0i22i3015.5119j0j7\&sourceid=chrome\&ie=UT F-8, diakses pada tanggal 16 April 2021.

Herdiana, D. (2019). Peran Masyarakat Dalam Pengembangan Desa Wisata Berbasis Masyarakat. JUMPA. $6(1)$

Hidayah, Ni'mah. Hutagalung, S \& Hermawan, D. (2019). Analisis Peran Stakeholder Dalam Pengembangan Wisata Talang Air Peninggalan Kolonial Belanda di Kelurahan Pajaresuk Kabupaten Pringsewu. Jurnal Administrasi Publik. 7(1)

Karta. N.L Putu. Kusumawijaya, I.K \& Kappola, V.B. (2020). The Roles and Contributions of Stakeholders in Villages Tourism Brand Management in Bali and India. Journal of Bali Studies. 10. (1).

Kurniawan, Fandy, Soesilo Zuhar \& Hermawan. Kemitraan Pengelolaan Sektor Pariwisata (Studi Pada Tirta Wisata Kabupaten Jombang). Jurnal Administrasi Publik. 1(1)

Kurniawati, E. Hamid D \& Hakim, L. (2018). Peran Masyarakat Dalam Perencanaan Dan Pengembangan Desa Wisata Tulungrejo Kecamatan Bumiaji Kota Batu. Jurnal Administrasi Bisnis. 54(1)

Lubis, F.R.A., Suharyanto, A., Effendy, R., Meidasari, V.E., Shahnaz, L. (2020). Role of Facebook Advertising in Promoting Tourism in Asia. International Journal of Psychosocial Rehabilitation, 24(1).

Maliki, M. (2021). Siosar Menjadi Pengembangan Pariwisata Andalan Karo. Website: (https://waspada.id/ features/siosarmenjadipengembangan-pariwisata-andalan-karo/, diakses pada tanggal 15 April 2021)

Ratnaningsih, NL Gede \& Mahagangga, I Gst. Agung Oka. (2015). Partisipasi Masyarakat Lokal Dalam Pariwisata (Studi Kasus Di Desa Wisata Belimbing, Tabanan, Bali). Jurnal Destinasi Wisata. 3(1)

Sagita Purnomo. 2018. Melibatkan swasta dalam Pembangunan Pariwisata. (https://www.jurnalasia.com/opini/melibatkan-swasta-dalam-pembangunan-pariwisata/, diakses pada 15 April 2021)

Simamora, R.K., dan Rudi S.S., (2016). Peran Pemerintah Daerah dalam Pengembangan Pariwisata Alam dan Budaya di Kabupaten Tapanuli Utara, JPPUMA: Jurnal Ilmu Pemerintahan dan Sosial Politik UMA (Journal of Governance and Political UMA), 4 (1): 79-96. 
Simanjorang, F. Hakim, L \& Sunarti. (2020). Peran Stakeholder Dalam Pembangunan Pariwisata Di Pulau Samosir. Jurnal Profit. 4(3).

Sinuhaji, V.V. Siregar, N.S.S. \& Jamil, B. (2019). Aktivitas Komunikasi Pemasaran Dinas Pariwisata Dan Kebudayaan

Kabupaten Karo Dalam Meningkatkan Kunjungan Wisatawan (Studi Deskriptif Kualitatif Wisata Bukit GundalingBerastagi), Administrasi Publik, Ilmu Komunikasi (JIPIKOM), 1(2) 2019: 101-114,

Suharyanto, A. Febryani, A. Wiflihani \& Batubara, B.M. (2019). Village Government Policy on Tourism Management in Situngkir Village Research Article in Proceedings of the 2nd International Conference on Social Sciences and Interdisciplinary Studies (formerly ICCSSIS), ICCSIS 2019, 24-25 October 2019, Medan, North Sumatera, Indonesia

Suharyanto, A., Barus, R. K. I., \& Batubara, B. M. (2020). Photography and Tourism Potential of Denai Kuala Village. Britain International of Humanities and Social Sciences (BIoHS) Journal, 2(1), 100-108.

Tarigan, T., (2020). Negeri di Atas Awan, Sisi Lain Potensi Pengembangan Siosar. Website:(https://www.kompasiana.com/teotarigan/5e2cf44ed541df1875019653/negeri-di-atasawan-sisi-lain-potensi-pengembangan-siosar?page=all , diakses pada tanggal 17 April 2021) 